\title{
Screening for Antiparasitic Activity of Crude Extracts of Pleurotus highking, a Bangladeshi Edible Mushroom
}

\author{
Md. Anwarul Haque ${ }^{1}$, Ashish Kumar Sarker ${ }^{1}$, Ratan Kumar Paul ${ }^{1}$, \\ Sultana Shakila Khan ${ }^{1}$ and Md. Anwar Ul Islam ${ }^{2}$ \\ ${ }^{1}$ Department of Pharmacy, Pabna University of Science and Technology, Pabna-6600, Bangladesh \\ ${ }^{2}$ Department of Pharmacy, University of Rajshahi, Rajshahi-6205, Bangladesh
}

Received: November 29, 2014; Accepted: January 15, 2015

\begin{abstract}
Compounds obtained from natural sources play significant role to identify various novel drug molecules. This study was designed to investigate parasitic susceptibility of methanolic extract from the Pleurotus highking, an edible mushroom commercially cultivated in Bangladesh against Pheretima posthuma. Extraction was carried out by continuous hot percolation method using methanol as a solvent. Four concentrations $(10,20,40 \mathrm{and} 80 \mathrm{mg} / \mathrm{ml})$ of the extract were used for screening and results were expressed in terms of the time paralysis and death of worms. The extract exhibited promising antiparasitic activity at the concentration of $80 \mathrm{mg} / \mathrm{ml}$. Albendazole and distilled water were used as reference standard and control, respectively. The extract showed its activity in the dose and time dependent manner. This is the first report of the antiparasitic activity of methanolic extract of $P$. highking.
\end{abstract}

Key words: Pleurotus highking, Antiparasitic, Pheretima posthuma, Edible mushroom

\section{Introduction}

Parasitic helminths affect animals and man, causing considerable hardship and stunted growth. Millions of human infections by helminths exist worldwide due to increased world travelling and immigration from the developing countries. In developing countries, they pose a large threat to public health and contribute to the prevalence of malnutrition, anemia, eosinophilia and pneumonia (Bundy et al., 1994). The helminths parasites mainly subsist human body in intestinal tract, but they are also found in tissue, as their larvae migrate towards them (Tripathi, 2003). Most diseases caused by helminths are chronic and debilitating in nature. They probably cause more morbidity and greater economic and social deprivation among humans and animals than any single group of parasites.

However, tremendous advances have been made during the previous decade and substantial numbers of synthetic precursors have been derived to cope up the damage caused by parasite, but unfortunately no effective medicine has been developed so far. Moreover, the problems associated with the use of such drugs, like some serious side effects and development of resistance intensify the infection to the next level. These factors encourage herbal remedies as alternative anthelmintics. Evaluation of activities of medicinal plants claimed for possessing the antiparasitic property is getting the attention these days. Searching for alternative strategies against gastrointestinal nematodes, has led to the proposal of screening medicinal plants for their anthelmintic activity.

From ancient times mushrooms are recognized as food items. Mushrooms contain a huge diversity of biomolecules with nutritional (Bala et al., 2011) and/or medicinal properties (Borchers et al., 2004; Lindequist et al., 2009; Kalac, 2009). Due to these properties, they have been recognized as functional foods, as well as a source for the development of medicines and nutraceuticals. In particular, mushrooms could be a source of natural antibiotics (Tehrani et al., 2012), which can be low molecular weight (LMW) and high Molecular Weight (HMW) (Alves et al., 2012) compounds. LMW compounds are mainly secondary metabolites such as sesquiterpenes and other terpenes, steroids, anthraquinone

Correspondence to: Md. Anwar U1 Islam, Email: profanwarulislam@yahoo.com 
and benzoic acid derivatives, and quinolines, but also primary metabolites such as oxalic acid and HMW compounds mainly include peptides and proteins (Ferreira et al., 2010).

In this study, Pleurotus highking, an edible oyster mushroom commercially cultivated in Bangladesh is subjected to investigate for its antiparasitic activity.

\section{Materials and Methods}

Sample Collection: The mushroom, Pleurotus highking was collected from National Mushroom Development and Extension Centre, Savar, Dhaka 1340, Bangladesh. The sample was dried at room temperature for 12 days, then placed in locked bags and stored at $25^{\circ} \mathrm{C}$.

Extraction of crude extract: The dried mushroom was ground to powder and these powdered materials $(50 \mathrm{~g})$ were mixed with $250 \mathrm{ml}$ of methanol in a beaker and placed on a rotary shaker for $24 \mathrm{~h}$. The methanol content was filtered using Whatman filter paper (No 4) and the solvent was evaporated for $15 \mathrm{~min}$ at $37^{\circ} \mathrm{C}$ using a rotary evaporator and crude extracts were obtained and preserved for experimental purpose.

Experimental parasites: All the experiments were carried out in adult earthworms (Pheretima posthuma) due to its anatomical resemblance with the intestinal roundworm parasites of human beings. They were collected from moist soil and washed with normal saline to remove all faecal matter. The earthworms of $8 \pm 1 \mathrm{~cm}$ in length and $0.1-0.2 \mathrm{~cm}$ in width were used for all the experimental protocol.

Preparation of Standard sample: Albendazole (Almex 400 mg, USP), Chewable Tablet, Square Pharmaceutical Ltd. Bangladesh) was prepared in different concentration $(10,20,40$ and $80 \mathrm{mg} / \mathrm{ml}$ ) by using $0.5 \%$ $\mathrm{w} / \mathrm{v}$ of carboxymethyl cellulose (CMC) as a suspending agent.

Preparation of test sample: The suspension of methanolic extract of Pleurotus highking of different concentration $(10,20,40$ and $80 \mathrm{mg} / \mathrm{ml})$ was prepared by using $0.5 \% \mathrm{w} / \mathrm{v}$ of CMC as a suspending agent and final volume was made up to $20 \mathrm{ml}$ for respective concentration. Albendazole and distilled water were used as standard and control, respectively. Worms with approximately equal size were divided into groups containing six earthworms in each group. Each worm of the groups was released into $20 \mathrm{ml}$ of corresponding concentrations of drug and extract in the petri dishes.

Experimental Design: The anthelmintic assay was carried as per the method of Ajaiyeoba et al. (2001) with minor modifications. The assay was performed on adult Pheretima posthuma earthworm. Due to easy availability, earthworms have widely been used for the initial evaluation of in vitro antiparasitic activity (Dash et al., 2002; Szewezuk et al., 2003; Shivkar et al., 2003). In the first set of experiment, six earthworms were released in to $20 \mathrm{ml}$ of solutions of albendazole and methanolic extract $(10,20,40$ and $80 \mathrm{mg} / \mathrm{ml} \mathrm{each})$ and distilled water. Albendazole was used as reference standard while distilled water as control. The required time for paralysis and the time for death of individual worms were recorded. Time for paralysis was noted when no movement of any sort could be observed except when the worms were shaken vigorously. Death was resolved when the worms lost their motility followed by fading away of their body colors (Nandan et al., 2011; Rastogi et al., 2009).

\section{Result and Discussion}

Preliminary phytochemical screening of the methanolic extract revealed the possible presence of anthraquinone glycosides, phenolic compounds, steroids, etc. The crude extract showed significant anthelmintic effect causing death of the worm at all the concentrations but the time of death was different in each case. However, in case of paralysis, significant variation among the results was observed at different concentrations. The methanolic extract of Pleurotus highking demonstrated comparable efficacy to albendazole in inducing paralysis as well as death of worms (Table 1). Albendazole causes flaccid paralysis resulting in expulsion of the worm by peristalsis. By increasing chloride ion conductance of worm muscle membrane albendazole produces hyperpolarisation and reduced excitability that leads to muscle relaxation and flaccid paralysis. Death worms are shown in Figure 1.

Helminths infections, repeatedly entitled helminthiasis are among the most pervasive infection and a foremost degenerative disease distressing a large proportion of world's population (Sangh et al., 2012). Chemical control of helminths along with improved management has been the important worm control strategy throughout the world. However, development of resistance 
in helminths against conventional anthelmintics is a foremost problem in treatment of helminths diseases (Geert et al., 1995; Coles et al., 1997). Natural resources have been exploited in the last years and among them, mushrooms could be an alternative source of new drugs for this treatment.
In this context, methanolic extract of Pleurotus highking, an edible mushroom commercially cultivated in Bangladesh was analyzed for its anthelmintic activity. The presented data showed a promising anthelmintic activity comparing with standard albendazole.

Table 1. Antiparasitic activity of extracts of Pleurotus highking.

\begin{tabular}{lccc}
\hline Sample & $\begin{array}{c}\text { Concentration } \\
\mathrm{mg} / \mathrm{ml}\end{array}$ & Paralysis (min) & Parameters \\
\hline Control & - & - & Death (min) \\
& 10 & $3.2 \pm 0.14$ & $66.3 \pm 0.07$ \\
Standard & 20 & $2.1 \pm 0.17$ & $46.5 \pm 0.13$ \\
& 40 & $0.8 \pm 0.11$ & $30.1 \pm 0.57$ \\
& 80 & $0.5 \pm 0.31$ & $15.9 \pm 0.38$ \\
& 10 & $5.1 \pm 0.18$ & $89.9 \pm 0.13$ \\
Extracts & 20 & $3.5 \pm 0.21$ & $55.8 \pm 0.17$ \\
& 40 & $1.3 \pm 0.15$ & $37.2 \pm 0.24$ \\
\hline
\end{tabular}

The values expressed as mean \pm SEM of 3-4 experiments.

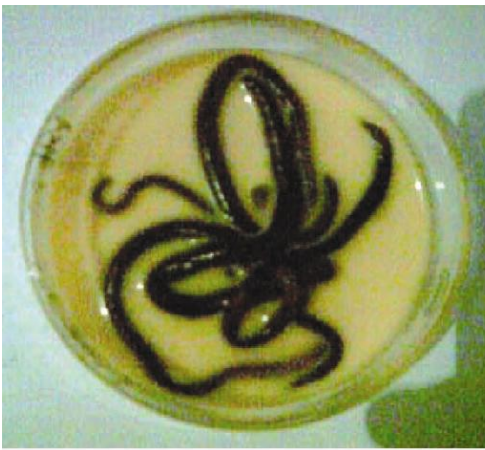

Albendazole

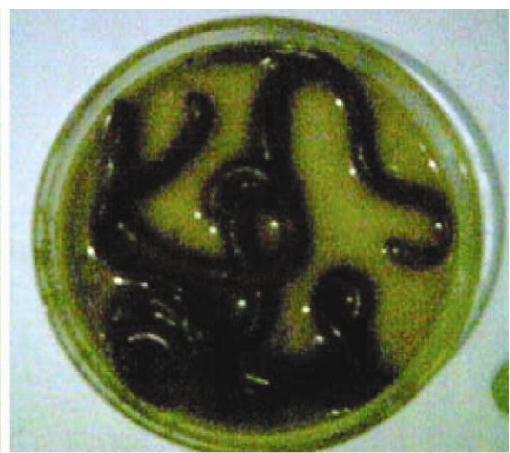

Methanolic extract

Figure 1. Screening of anthelmintic activity of Pleurotus highking extract.

Phytochemical analysis of the crude extract of oyster mushrooms revealed presence of flavonoids as one of the chemical constituent. Polyphenolic compounds show anthelmintic activity (Bate et al., 1962). Some synthetic phenolic anthelmintics e.g., niclosamide, oxyclozanide and bithionol are shown to interfere with energy generation in helminth parasites by uncoupling oxidative phosphorylation (Martin et al., 1997). It could be assumed that phenolic content in the extract of $P$. highking produced similar effects. To our best knowledge, there is no report on anthelmintic activity of the extract of $P$. highking mushroom and further study should be conducted in this regard.

\section{Conclusion}

Bioactive compounds from different mushrooms have diverse applications. Hence these compounds serve as basic platform to find out new and potential natural products. The present evaluation leads to conclude that the extract of $P$. highking have potent anthelmintic activity when compared with the conventionally used drug. Further studies using in vivo models and to isolate active constituents from extract are required to carry out and to 
establish the effectiveness and pharmacological rationale for the use of $P$. highking as an antiparasitic drug.

\section{References}

Ajaiyeoba, E.O., Onocha, P.A. and Olarenwaju, O.T. 2001. In vitro anthelmintic properties of Buchholzia coriaceae and Gynandropsis gynandra extract. Pharm. Biol. 39, 217-220.

Alves, M.J., Ferreira, I.C.F.R., Dias, J., Teixeira, V., Martins, A. and Pintado, M. 2012. A review on antimicrobial activity of mushroom (Basidiomycetes) extracts and isolated compounds. Planta. Med. 78, 1707-1718.

Bala, N., Aitken, E.A.B., Fechner, N., Cusack, A. and Steadman, K.J. 2011. Evaluation of antibacterial activity of Australian basidiomycetous macrofungi using a high-throughput 96well plate assay. Pharm. Biol. 49, 1-9.

Bate-Smith, E.C. 1962. The phenolic constituent of plants and their taxonomic significance, dicotyledons. J. Linn. Soc. Bot. 58, 95-103.

Borchers, A., Keen, C.L. and Gershwin, M.E. 2004. Mushrooms, tumors, and immunity: an update. Exp. Biol. Med. 229, 393406.

Bundy, D.A. 1994. Immunoepidemiology of intestinal helminthic infection: The global burden of intestinal nematode disease. Trans. Roy. Soc. Trop. Med. Hyg. 8, 259261

Coles, G.C. 1997. Nematode control practices and anthelmintic resistance on British sheep farms. Vet. Res. 141, 91-93.

Dash, G.K., Suresh, P., Kar, D.M., Ganpaty, S. and Panda, S.B. 2002. Evaluation of Evolvulus alsinoids Linn. for anthelmintic and antimicrobial activities. J. Nat. Rem. 2, 182-185.

Ferreira, I.C.F.R., Vaz, J.A., Vasconcelos, M.H. and Martins, A. 2010. Compounds from wild mushrooms with antitumor potential. Anticancer Agents Med. Chem. 10, 424-436.
Geert, S. and Dorny, P. 1995. Anthelmintic resistance in helminths of animals and man in the tropics. Dutre. Mer. 3, 401-423.

Kalac, P. 2009. Chemical composition and nutritional value of European species of wild growing mushrooms: A review. Food Chem. 113, 9-16.

Lindequist, U., Niedermeyer, T.H.J. and Julich, W.D. 2005. The pharmacological potential of mushrooms. Evid. Based Complement Alternat. Med. 2, 285-299.

Martin, R.J. 1997. Mode of action of anthelmintic drugs. Vet. J. 154, 11-34.

Nandan, Y.D. 2011. Evaluation of anthelmintic activity of leaves of Paederia foetida. Int. J. Pharma. Bio Sci. 2, 227-231.

Rastogi, T., Vijay, B., Komal, M., Aswar, P.B. and Khadabadi, S.S. 2009. Comparative studies on anthelmintic activity of Moringa Oleifera and Vitex Negundo. Asi. J. Res. Chem. 2, 181-182.

Sangh, P., Saurabh, K., Amit, K., Neeraj, K.S. and Jha. K.K. 2012. In-vitro anthelmintic activity of Luffa cylindrica leaves in Indian adult earthworm. J. Pharmacog. Phytochem. 1, 27-30.

Shivkar, Y.M. and Kumar, V.L. 2003. Anthelmintic activity of latex of Calotropis procera. Pharm. Biol. 41, 263-265.

Szewezuk, V.D., Mongelli, E.R. and Pomilio, A.B. 2003. Antiparasitic activity of Melia azadirach growing in Argentina. Mol. Med. Chem. 1, 54-57.

Tehrani, M.H.H., Fakhrehoseini, E., Nejad, M.K., Mehregan, H. and Hakemi,V.M. 2012. Search for proteins in the liquid extract of edible mushroom, Agaricus bisporus, and studying their antibacterial effects. Iran. J. Pharm. Res. 11, 145-150.

Tripathi, K.P. 2003. Essentials of meditional pharmacology. $5^{\text {th }}$ Edn, Jaypee Brothers Medical Publishers (P) LTD, New Delhi, p. 759. 